\title{
Welcome by Professor Giovanni Pilato
}

Dear Friends,

I am very glad to have you in Catania for our Tenth International Symposium and to see again some old friends, some of whom I first met at the first Symposium in Pallanza (more than thirty years ago), and I am glad to see many young colleagues who have chosen to study such an interesting animal group and who represent the future of tardigrade research (even if old men like me have no intention of retiring just yet). I have seen with great satisfaction the flourishing of diversified research: Morphology, Systematics, Ecology, Biology, new Methodologies, especially the extraordinary property of cryptobiosis, are studied by many tardigradologists, and the molecular surveys are no longer sporadic. I hope that nobody will commit the mistake of separating the ecological or biological research from the systematics. Today this error is becoming more and more frequent in many fields; but what is the value of an ecological or biological study without a correct specific diagnosis? The tendency to not emphasize morphology and systematics is today evident but I am not discouraged. I have studied animal morphology, systematics and phylogenesis for more than forty years and I can affirm that good research on systematics, with the emphasis on good research, will always be necessary, and phylogenesis is one of the most interesting chapters of biology.

Before we begin our work, I must emphasize that it would have been impossible to organize this symposium without the concrete support of some public and private organizations that luckily helped us. So, together with the Organizing Committee, I am happy to thank the University of Catania, the University of Modena and Reggio Emilia, the Faculty of Sciences of the University of Catania, the Parco dell'Etna, the Azienda Provinciale per il Turismo di Catania (APT), the CUTGANA of the University of Catania, the Ente Fauna Siciliana, the Parco Scientifico e Tecnologico della Sicilia, the Provincia Regionale di Catania (Assessorato alle Politiche Ambientali) the Accademia Gioenia di Scienze Naturali di Catania, the Area Marina Protetta Isola dei Ciclopi, the Department of Animal Biology, the Department of Botany and the Faculty of Humanities and Philosophy of the University of Catania, the Department of Animal Biology of the University of Modena and Reggio Emilia, the A.S. Biotechnology of Catania (represented by our friend Edy Bonaccorso), Leica Microinstruments of Milano, the Director of the Library "Civica - Ursino Recupero" of Catania Dr. Rita Carbonaro and particularly the owner of the telpherage of Mount Etna, Dr. Gioacchino Russo, because we will be their guests on the last day of the Symposium.

For their collaboration I would like to thank all the members of the Organizing Committee and many other colleagues and friends who in various ways helped me in the organization of the Symposium.

Together with the Organizing Committee, I thank you who, coming from many (14) countries of the world, are here to bring prestige to the Symposium and to share in the scientific progress by comparing and discussing results and experiences. Certainly you know the difficulties concerning the organization of a Symposium, and therefore you will forgive some unavoidable imperfections.

I am glad to see here the majority of tardigradologists, and I would like to send my best wishes to those colleagues who for various reasons are not able to be here (with a particular affection for Sandra Claxton and Jim Garey). Finally, I would also like to emphasize that our research, even if the problems, approaches, and techniques change and improve, come from the work of scientists of the past (remote and recent) and therefore I wish, and I think that all of you agree, to thank the tardigradologists that are no longer with us, and to dedicate this Symposium to them.

Thank you to all participants. 